\title{
Safety analysis of two different regimens of uracil-tegafur plus leucovorin as adjuvant chemotherapy for high-risk stage II and III colon cancer in a phase III trial comparing 6 with 18 months of treatment: JFMC33-0502 trial
}

\author{
Takashi Tsuchiya $\cdot$ Sotaro Sadahiro $\cdot$ Kazuaki Sasaki $\cdot$ Ken Kondo Kenji Katsumata Genichi Nishimura \\ Yoshihiro Kakeji · Hideo Baba · Takayuki Morita $\cdot$ Keiji Koda $\cdot$ Seiji Sato · Junji Matsuoka • \\ Yoshiyuki Yamaguchi · Hisashi Usuki · Chikuma Hamada · Susumu Kodaira · Shigetoyo Saji
}

Received: 25 February 2014 / Accepted: 23 March 2014 / Published online: 18 April 2014

(C) The Author(s) 2014. This article is published with open access at Springerlink.com

\begin{abstract}
Purpose The JFMC33-0502 trial is a phase III clinical study designed to determine the most appropriate duration of postoperative adjuvant chemotherapy with uracil-tegafur (UFT) plus leucovorin in patients with stage IIB or III colon cancer. We report the interim results of preplanned safety analyses.

Methods Patients with stage IIB or III colon cancer who had undergone curative resection were randomly assigned to receive UFT $\left(300 \mathrm{mg} / \mathrm{m}^{2}\right)$ plus leucovorin $(75 \mathrm{mg} /$ day $)$ for 6 months (control group, 4 weeks of treatment followed
\end{abstract}

Electronic supplementary material The online version of this article (doi:10.1007/s00280-014-2461-5) contains supplementary material, which is available to authorized users.

T. Tsuchiya $(\square)$

Sendai City Medical Center, 5-22-1 Tsurugaya, Miyagino-ku,

Sendai 983-0824, Japan

e-mail: tsuchiya@openhp.or.jp

S. Sadahiro

Tokai University, Isehara, Japan

K. Sasaki

Otaru Ekisaikai Hospital, Otaru, Japan

K. Kondo

National Hospital Organization Nagoya Medical Hospital,

Nagoya, Japan

K. Katsumata

Tokyo Medical University, Tokyo, Japan

G. Nishimura

Japanese Red Cross Kanazawa Hospital, Kanazawa, Japan

Y. Kakeji

Kobe University, Kobe, Japan by a 1-week rest, five courses) or for 18 months (study group, 5 days of treatment followed by a 2-day rest, 15 courses). Treatment status and safety were evaluated.

Results A total of 1,071 patients were enrolled, and 1,063 were included in safety analyses. Treatment completion rate at 6 months was $74.0 \%$ in the control group and $76.7 \%$ in the study group. Treatment completion rate in the study group at 18 months was $56.0 \%$. The overall incidence of adverse events (AEs) was $75.3 \%$ in the control group and $77.6 \%$ in the study group. The incidences of grade 3 or higher AEs were low in both groups. During the first 6 months, the incidences of the subjective AEs were significantly lower in the study group.

Conclusions Oral UFT plus leucovorin given by either dosage schedule is a very safe regimen for adjuvant

H. Baba

Kumamoto University, Kumamoto, Japan

T. Morita

Aomori Prefectural Central Hospital, Aomori, Japan

K. Koda

Teikyo University Chiba Medical Center, Ichihara, Japan

S. Sato

School of Medicine, Fujita Health University, Toyoake, Japan

J. Matsuoka

Okayama University Hospital, Okayama, Japan

Y. Yamaguchi

Kawasaki Medical School, Kurashiki, Japan

H. Usuki

Kagawa University, Kagawa, Japan

C. Hamada

Tokyo University of Science, Tokyo, Japan 
chemotherapy. In particular, 5 days of treatment followed by a 2-day rest was a useful treatment option from the viewpoint of toxicity even when given for longer than 6 months.

Keywords Colon cancer - Adjuvant chemotherapy · Uracil-tegafur (UFT) · Leucovorin · Treatment duration

\section{Introduction}

Adjuvant chemotherapy is standard treatment for stage III colon cancer and has also been recommended for the management of high-risk stage II colon cancer [1]. Several studies have examined the optimal duration of postoperative adjuvant chemotherapy, but clear conclusions were not obtained [2-4].

In recent studies of adjuvant chemotherapy for colon cancer performed in Western countries, the duration of treatment was 6 months for regimens, such as 5-fluorouracil plus leucovorin, oral uracil-tegafur (UFT) plus leucovorin, oral capecitabine, and FOLFOX (oxaliplatin, 5-fluorouracil, and leucovorin) [5-7]. Therefore, 6 months of adjuvant chemotherapy has been standard, even in routine clinical practice.

An analysis of the Adjuvant Colon Cancer Endpoints (ACCENT) database showed that recurrence of colorectal cancer reaches a peak between 1 and 2 years after surgery [8]. Sadahiro et al. [9] reported that the cumulative recurrence rate of colon cancer in their series was $43 \%$ at 1 year and $77 \%$ at 2 years. This finding suggests that adjuvant chemotherapy for longer than 6 months may more significantly reduce recurrence and improve survival rates. In clinical trials performed in Japan, 1 year or 2 years of postoperative adjuvant chemotherapy with UFT alone significantly improved survival rates as compared with surgery alone in patients with rectal or colorectal cancer [10,11]. In patients with stage I lung adenocarcinoma, 2 years of UFT monotherapy revealed significant impact on survival [12]. The optimal duration of adjuvant chemotherapy may thus differ according to the type of cancer and treatment regimen.

We conducted a large phase III clinical trial comparing 6 months with 18 months of oral UFT plus leucovorin to determine the optimal duration of postoperative adjuvant chemotherapy for patients with high-risk stage II and stage III colon cancer.

S. Kodaira

Nerima General Hospital, Tokyo, Japan

S. Saji

Japanese Foundation for Multidisciplinary Treatment of Cancer,

Tokyo, Japan
We report the interim results of a preplanned safety analysis of adverse events (AEs) and an analysis of completion rates.

\section{Materials and methods}

This study was conducted in accordance with the Declaration of Helsinki and ethical guidelines for clinical research (overall revision dated December 28, 2004) and was approved by the institutional review boards of each participating hospital. Written informed consent was obtained from all patients who participated in the study.

The main eligibility criteria were as follows: (1) a histologically confirmed colorectal cancer; (2) a pathological classification of stage IIB (T4, N0, M0), IIIA (T1-2, N1, M0), IIIB (T3-4, N1, M0), or IIIC (any T, N2, M0) cancer of the colon (cecum, ascending colon, transverse colon, descending colon, sigmoid colon) or rectum (only the rectosigmoid) according to the sixth edition of tumornode-metastasis classification of the International Union against Cancer; (3) radical resection of colorectal cancer with extended (D2 or more) lymph node dissection; (4) histologic curative resection; (5) aged 20-75 years; (6) an Eastern Cooperative Oncology Group performance status (PS) of 0 or 1 ; (7) no previous chemotherapy or radiotherapy; (8) ability to orally ingest a normal diet and to receive oral drugs; (9) adequate organ function; (10) ability to start postoperative adjuvant chemotherapy within 6 weeks after surgery.

Patients who were confirmed to be eligible and enrolled were randomly assigned to receive UFT plus leucovorin for 6 months (control group, standard treatment) or for 18 months (study group, study treatment). The treatment assignments were randomized at the registration office. A minimization method was used to balance assignments according to the following stratifying factors: TNM $\mathrm{T}$ category (T1-2, T3, T4), $\mathrm{N}$ category (N0, N1, N2), surgical procedure (laparoscopic surgery, open surgery), and hospital. The study investigators and patients were not blinded to the treatment assignments.

The control group received UFT $\left(300 \mathrm{mg} / \mathrm{m}^{2} /\right.$ day as tegafur) orally in three divided doses per day (every about $8 \mathrm{~h}$ ), avoiding $1 \mathrm{~h}$ before and after meals. Leucovorin $(75 \mathrm{mg} /$ day) was given orally in three divided doses per day at the same times as UFT. Drugs were administered for 28 consecutive days, followed by a 7-day rest (consecutive-day treatment), and this was defined as one course of treatment. Five courses of treatment (6 months) were administered. The study group received UFT plus leucovorin at the same dose level as the control group. The drugs were administered orally for five consecutive days, followed by a 2-day rest. Five weeks of this regimen (5 days 

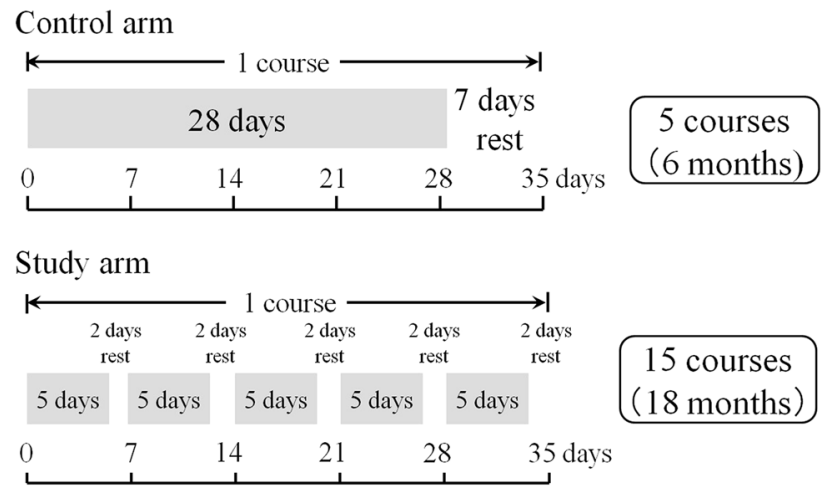

Fig. 1 Dose schedule

of treatment followed by a 2-day rest on Saturday and Sunday) were defined as one course of treatment, and 15 courses (18 months) were administered (Fig. 1).

After completing the scheduled number of treatment courses in each group, patients were followed up with no further treatment until confirmation of metastasis or recurrence.

The assigned treatment was started within 6 weeks after surgery. During protocol treatment, clinical findings and laboratory data were evaluated every 2 weeks during the first two courses of treatment and then on the day of starting each subsequent course. The following conditions had to be met at the start of each course: white cell count $\geq 3 \times 10^{3} / \mu \mathrm{L}$ and $<12 \times 10^{3} / \mu \mathrm{L}$, neutrophil count $\geq 1,500 / \mu \mathrm{L}$, hemoglobin level $\geq 9.0 \mathrm{~g} / \mathrm{dL}$, platelet count $\geq 100 \times 10^{3} / \mu \mathrm{L}$, serum total bilirubin level $<1.5 \mathrm{mg} / \mathrm{dL}$, serum aspartate aminotransferase and alanine aminotransferase levels $<100 \mathrm{IU} / \mathrm{L}$, serum creatinine level $<1.5 \mathrm{mg} / \mathrm{dL}$, no diarrhea (watery stools), and $\leq$ grade 1 nonhematologic toxicity (with the exception of constipation, alopecia). If the criteria for starting/continuing treatment were not met, treatment was postponed or suspended until AEs resolved, and the criteria for treatment resumption were met. If the treatment was suspended because of grade 3 or higher AEs, only the dose of UFT was reduced by one level when the treatment was resumed. After resuming treatment at one lower dose level, the dose of UFT was not increased again, even if the toxicity resolved.

The criteria for discontinuing protocol treatment were as follows: the presence of progressive disease (metastasis or recurrence); serious AEs and complications that preclude the continuation of treatment; a request by the patient; inability to resume treatment within 21 days after treatment suspension; the same toxicity occurs after reducing the dose of UFT by two levels; and the study investigator judges that the continuation of the study treatment is not feasible.
Data collection

\section{Treatment status}

Treatment status, such as the daily dose, number of dosing, treatment suspension, dose reduction, and treatment discontinuation, was collected from the case report forms of each patient. The treatment completion rate was defined as the percentage of patients who completed five courses of treatment in the control group and the percentage of patients who completed 15 courses of treatment in the study group.

\section{Safety profile}

Adverse events were evaluated according to the Common Terminology Criteria for adverse Events (CTCAE), Japanese translation, version 3.0, prepared by the Japan Clinical Oncology Group (JCOG) and Japan Society of Clinical Oncology (JSCO). The most severe grade of AEs up to 30 days after the completion of treatment was recorded. The following categories of AEs were listed in the case report forms, and evaluation of the grade was required: hemoglobin level, white cell count, neutrophil count, platelet count, serum aspartate aminotransferase and alanine aminotransferase levels, serum alkaline phosphatase level, serum total bilirubin level, serum blood urea nitrogen level, serum creatinine level, anorexia, nausea, vomiting, stomatitis, diarrhea, rash or desquamation, hand-foot skin reactions, alopecia, easily fatigued (asthenia, malaise, and narcolepsy), and arrhythmias. Statistical analysis was performed with the use of SAS software, release 9.2 (SAS Institute, Cary, NC, USA). The Pearson chi-square test was conducted to compare the rate of AEs between arms at twotailed 0.05 significant level.

\section{Results}

Patient characteristics

From October 2005 through September 2007, a total of 1,071 patients were enrolled from 233 hospitals in Japan. After excluding 8 patients because of the reasons shown in Fig. 2, 1,063 patients were included in the safety analysis (control group, 531 patients; study group, 532 patients). All data were finalized on February 2013. Table 1 shows the demographics of the 1,063 patients.

\section{Treatment status}

The completion rate of protocol treatment at 6 months was similar in the control group (74.0\%) and in the study group 
Fig. 2 Allocation of patients

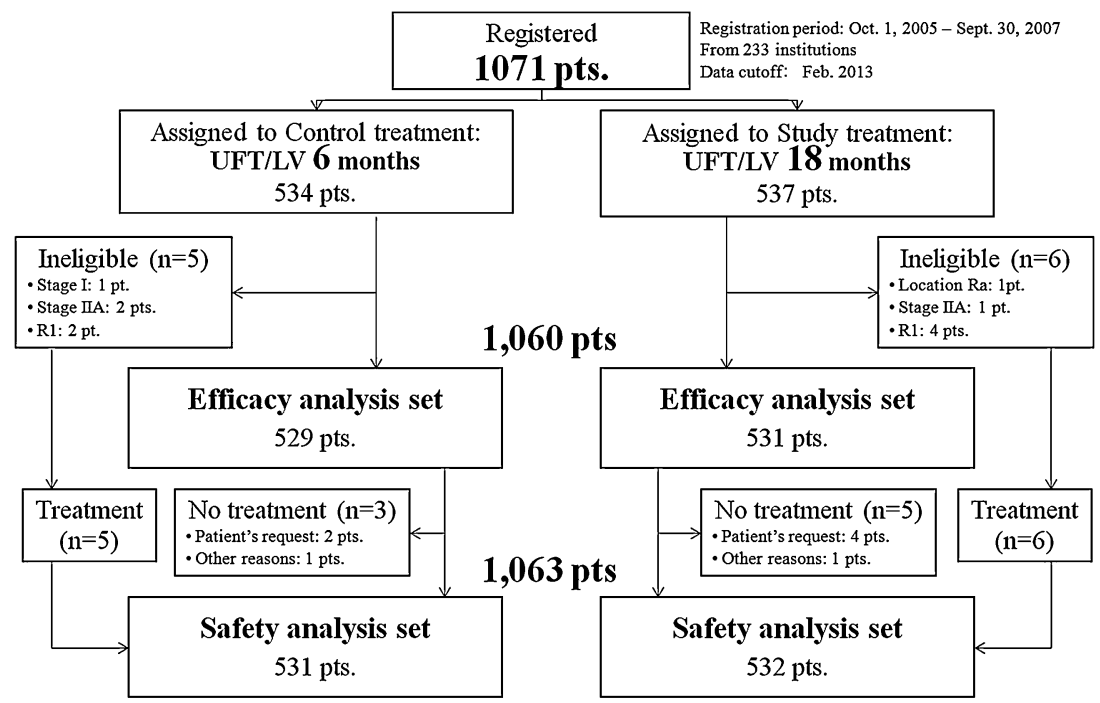

(76.7\%). The final treatment completion rate in the study group was $56.0 \%$ (Table 2).

Dose reduction was required in $15.3 \%$ of patients in the control group as compared with $9.8 \%$ in the study group at 6 months. Treatment suspension was observed at $36.0 \%$ of patients in the control group and $33.6 \%$ in the study group (Table 3). As for the reasons for discontinuing treatment, the proportion of patients who stopped to continue treatment for reasons other than AEs was higher in the study group than in the control group (Table 4). In patients who discontinued treatment because of AEs, the number of patients who discontinued the treatment during the first course of treatment was higher in the control group (31 patients) than in the study group (12 patients) (Fig. 3).

\section{Safety profile}

At the completion of 5 courses of treatment, AEs at any grade had been reported in $75.3 \%$ of patients in the control group and $69.2 \%$ of those in the study group. The rates of grade 3 or higher AEs were $16.2 \%$ in the control group and $10.0 \%$ in the study group. Table 5 shows AEs at the completion of 5 courses of treatment. The incidences of AEs in hemoglobin levels, blood urea nitrogen levels, anorexia, nausea, vomiting, stomatitis, diarrhea, and fatigue (any grade) were significantly lower in the study group than in the control group. The rate of grade 3 or higher diarrhea was $7.2 \%$ in the control group and $2.4 \%$ in the study group. During treatment courses 6-10 (6-12 months) and 11-15 (12-18 months) in the study group, the incidences of grade 3 or higher AEs were $1 \%$ or less (Table 6). Moreover, the incidences of nonhematologic toxicity, including anorexia, nausea, diarrhea, and fatigue, tended to be low. The overall incidence of AEs during 15 courses of treatment in the study group was $77.6 \%$; the incidence of grade
3 or higher AEs was $14.1 \%$. There was no treatmentrelated death in either group.

\section{Discussion}

The NSABP C06 study showed that oral UFT plus leucovorin is noninferior to intravenous 5 -fluorouracil plus leucovorin in patients with stage II or III colon cancer [5]. The JCOG0205 study confirmed the noninferiority of oral UFT plus leucovorin to intravenous fluorouracil and leucovorin in Japanese patients with stage III colon cancer [13]. These results established oral UFT plus leucovorin as one of a standard regimen for postoperative adjuvant chemotherapy in patients with colon cancer [14]. The standard duration of adjuvant chemotherapy has been 6 months in Western countries. However, a retrospective study of patients with stage III colon cancer who were 65 years or older reported that patients who received 5-fluorouracil-based chemotherapy for 5-7 months had better overall survival than those who received similar therapy for 1-4 months [15].

Present study was conducted to evaluate the effectiveness of prolongation of treatment duration in adjuvant chemotherapy with oral UFT plus leucovorin. The control group received oral UFT plus leucovorin for four consecutive weeks followed by a 1-week rest, a conventionally used regimen, for 6 months. In the study group, oral UFT plus leucovorin was given for 5 days followed by a 2-day rest and a treatment schedule associated with mild toxicity and good compliance, for a total of 18 months.

The incidence of AEs was lower in the study group $(69.2 \%)$ than in the control group $(75.3 \%)$ at 6 months. Even at the completion of 18-month treatment in the study group, the incidence of AEs $(77.6 \%)$ was similar to that at 6 months in the control group. In the study group, 
Table 1 Patient characteristics

\begin{tabular}{|c|c|c|c|c|c|c|}
\hline & \multicolumn{2}{|c|}{ Control group } & \multicolumn{2}{|c|}{ Study group } & \multicolumn{2}{|l|}{ Total } \\
\hline & $n=534$ & $\%$ & $n=537$ & $\%$ & $n=1,071$ & $\%$ \\
\hline \multicolumn{7}{|l|}{ Gender } \\
\hline Male & 294 & 55.1 & 264 & 49.2 & 558 & 52.1 \\
\hline Female & 240 & 44.9 & 273 & 50.8 & 513 & 47.9 \\
\hline \multicolumn{7}{|l|}{ Age } \\
\hline$\leq 50$ & 51 & 9.6 & 51 & 9.5 & 102 & 9.5 \\
\hline $51-60$ & 140 & 26.2 & 154 & 28.7 & 294 & 27.5 \\
\hline $61-70$ & 231 & 43.3 & 228 & 42.5 & 459 & 42.9 \\
\hline $71-80$ & 112 & 21.0 & 104 & 19.4 & 216 & 20.2 \\
\hline Median & \multicolumn{2}{|l|}{$64[23-75]$} & \multicolumn{2}{|l|}{$64[24-75]$} & \multicolumn{2}{|l|}{$64[23-75]$} \\
\hline \multicolumn{7}{|l|}{ PS } \\
\hline 0 & 503 & 94.2 & 517 & 96.3 & 1,020 & 95.2 \\
\hline 1 & 31 & 5.8 & 20 & 3.7 & 51 & 4.8 \\
\hline \multicolumn{7}{|l|}{ Tumor location } \\
\hline Right colon $(\mathrm{C}, \mathrm{A}, \mathrm{T})$ & 199 & 37.3 & 218 & 40.6 & 417 & 39.0 \\
\hline Left colon $(\mathrm{D}, \mathrm{S})$ & 221 & 41.4 & 211 & 39.3 & 432 & 40.3 \\
\hline Rs & 114 & 21.3 & 108 & 20.1 & 222 & 20.7 \\
\hline \multicolumn{7}{|l|}{ Operative procedure } \\
\hline Laparoscopic & 109 & 20.4 & 110 & 20.5 & 219 & 20.4 \\
\hline Laparotomy & 425 & 79.6 & 427 & 79.5 & 852 & 79.6 \\
\hline \multicolumn{7}{|l|}{ Histologic types } \\
\hline Wel & 187 & 35.0 & 190 & 35.4 & 377 & 35.2 \\
\hline Mod & 308 & 57.7 & 307 & 57.2 & 615 & 57.4 \\
\hline Por & 19 & 3.6 & 20 & 3.7 & 39 & 3.6 \\
\hline Muc & 20 & 3.7 & 18 & 3.4 & 38 & 3.5 \\
\hline Sig & 0 & 0.0 & 2 & 0.4 & 2 & 0.2 \\
\hline \multicolumn{7}{|l|}{ T (TNM 6th) } \\
\hline $\mathrm{T} 1$ & 16 & 3.0 & 16 & 3.0 & 32 & 3.0 \\
\hline $\mathrm{T} 2$ & 51 & 9.6 & 45 & 8.4 & 96 & 9.0 \\
\hline $\mathrm{T} 3$ & 283 & 53.0 & 272 & 50.7 & 555 & 51.8 \\
\hline $\mathrm{T} 4$ & 184 & 34.5 & 204 & 38.0 & 388 & 36.2 \\
\hline \multicolumn{7}{|l|}{ N (TNM 6th) } \\
\hline No & 69 & 12.9 & 75 & 14.0 & 144 & 13.4 \\
\hline $\mathrm{N} 1$ & 347 & 65.0 & 352 & 65.5 & 699 & 65.3 \\
\hline N2 & 118 & 22.1 & 110 & 20.5 & 228 & 21.3 \\
\hline \multicolumn{7}{|l|}{ Stage (TNM 6th) } \\
\hline I & 1 & 0.2 & 0 & 0.0 & 1 & 0.1 \\
\hline IIA & 2 & 0.4 & 1 & 0.2 & 3 & 0.3 \\
\hline IIB & 66 & 12.4 & 74 & 13.8 & 140 & 13.1 \\
\hline IIIA & 59 & 11.0 & 57 & 10.6 & 116 & 10.8 \\
\hline IIIB & 288 & 53.9 & 295 & 54.9 & 583 & 54.4 \\
\hline IIIC & 118 & 22.1 & 110 & 20.5 & 228 & 21.3 \\
\hline \multicolumn{7}{|l|}{ Extent of LN dissection } \\
\hline D2 & 147 & 27.5 & 136 & 25.3 & 283 & 26.4 \\
\hline D3 & 387 & 72.5 & 391 & 72.8 & 778 & 72.6 \\
\hline \multicolumn{7}{|l|}{ No. of LN examined } \\
\hline$<12$ & 165 & 30.9 & 151 & 28.1 & 316 & 29.5 \\
\hline$\geq 12$ & 369 & 69.1 & 386 & 71.9 & 755 & 70.5 \\
\hline
\end{tabular}


Table 2 Rates of treatment completion

\begin{tabular}{|c|c|c|c|c|}
\hline \multirow[t]{2}{*}{ Total } & \multicolumn{2}{|c|}{$\begin{array}{l}\text { Control group } \\
\text { (6 months) }\end{array}$} & \multicolumn{2}{|c|}{$\begin{array}{l}\text { Study group } \\
\text { (18 months) }\end{array}$} \\
\hline & $n=531$ & $\%$ & $n=532$ & $\%$ \\
\hline Discontinuation in $1-5$ courses & 138 & 26.0 & 124 & 23.3 \\
\hline $6-10$ courses & & & 70 & 13.2 \\
\hline $11-15$ courses & & & 35 & 6.6 \\
\hline Unknown & 0 & 0.0 & 1 & 0.2 \\
\hline \multirow{2}{*}{$\begin{array}{l}\text { Treatment completion in } 1-5 \\
\text { courses ( } 6 \text { months) }\end{array}$} & 393 & 74.0 & 298 & 56.0 \\
\hline & 393 & 74.0 & 408 & 76.7 \\
\hline
\end{tabular}

Table 3 Percentages of patients who required dose reduction and those who discontinued treatment during 1-5 courses of treatment (6 months)

\begin{tabular}{llll}
\hline & $\begin{array}{l}\text { Control group } \\
(n=531)(\%)\end{array}$ & $\begin{array}{l}\text { Study group } \\
(n=532)(\%)\end{array}$ & $\begin{array}{l}\text { Total } \\
(n=1,052)(\%)\end{array}$ \\
\hline \multicolumn{2}{l}{ Dose reduction } \\
$(-)$ & 84.7 & & \\
$(+)$ & 15.3 & 90.2 & 87.5 \\
Treatment discontinuation & 9.8 & 12.5 \\
$(-)$ & 64.0 & 66.4 & 65.2 \\
$(+)$ & 36.0 & 33.6 & 34.8 \\
\hline
\end{tabular}

Table 4 Reasons for discontinuation during 1-5 courses of treatment (6 months)

\begin{tabular}{lccccr}
\hline Reason for discontinuation & \multicolumn{2}{c}{ Control group } & & \multicolumn{2}{c}{ Study group } \\
\cline { 2 - 3 } & $n=138$ & $\%$ & & $n=124$ & $\%$ \\
\hline Severe AEs & 2 & 1.4 & 6 & 4.8 \\
$\quad$ Hematologic toxicity & 30 & 21.7 & 20 & 16.1 \\
Nonhematologic toxicity & 30 & 3.6 & 4 & 3.2 \\
$\quad$ Complication & 5 & & & \\
Patient refusal & 14 & 10.1 & 23 & 18.5 \\
$\quad$ Reasons other than AEs & 30 & 21.7 & 11 & 8.9 \\
Because of AEs & 32 & 23.2 & 37 & 29.8 \\
Over rest period & 25 & 18.1 & 23 & 18.5 \\
Others & & & & \\
\hline
\end{tabular}

the incidences of nonhematologic toxic effects, such as anorexia, diarrhea, and fatigue (i.e., symptoms likely to affect treatment compliance), were significantly lower than that associated with the conventional treatment schedule in the control group. These findings suggested that treatment for 5 days followed by 2 days of rest contributed to lower incidences of AEs during 18 months of anticancer therapy.

At 6 months, the rate of discontinuing treatment because of AEs was $21.7 \%$ in the control group as compared with only $8.9 \%$ in the study group. This finding is

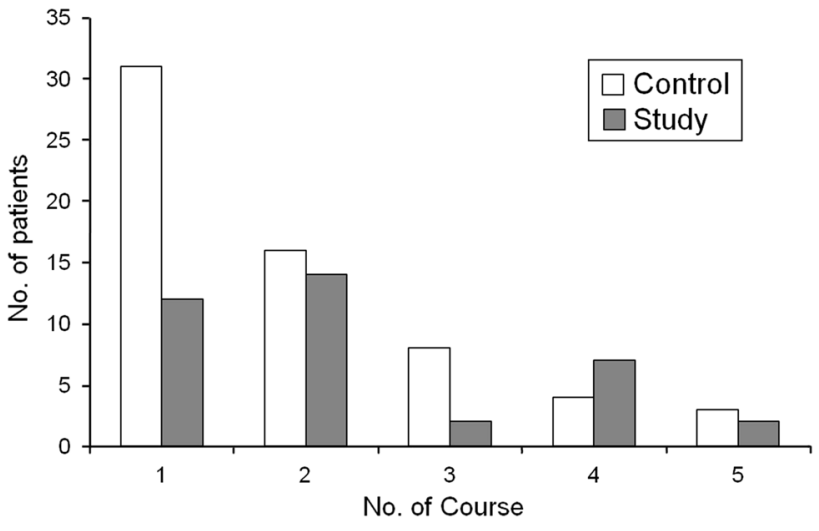

Fig. 3 Adverse events responsible for discontinuation during 1-5 courses of treatment

considered to reflect the milder AEs associated with the treatment schedule in the study group. The most common grade 3 or higher AE was diarrhea $(7.2 \%)$ in the control group. The incidences of all other grade or higher AEs were less than $5 \%$ in both groups. These results showed that both treatment schedules were acceptable as regimens for postoperative adjuvant chemotherapy; however, 5 days of treatment followed by 2 day of rest can be more strongly recommended for long-term treatment because of the lower incidences of AEs. The rate of completing 18 months of treatment in the study group was only $56.0 \%$ although the incidence of AEs was low. One possible reason might be the financial burden associated with the prolonged duration of treatment. Patients participating in the Japanese national health insurance system generally have to directly pay $30 \%$ of total medical fees. Consequently, patients would have to pay about 10,000 U.S. dollars ( 1 million yen) to complete 18 months of treatment in the study group. In fact, the proportion of patients who requested to discontinue treatment for reasons other than AEs was higher in the study group $(18 \%, 43 / 233)$ than in the control group $(10.1 \%$, 14/139), suggesting the involvement of economic factors. To our knowledge, no previous study has reported on the completion rate of 6 months or more of adjuvant chemotherapy with UFT and leucovorin in patients with colorectal cancer. One study evaluating 2 years of treatment with UFT alone without leucovorin in patients who underwent radical resection of Dukes B or C colon cancer, performed by the Tokai Adjuvant Chemotherapy Study Group for Colorectal (TAC-CR), reported that $69.7 \%$ of patients completed 1 year or more of treatment [11]. In another study assessing 1 year of treatment with UFT alone in patients who underwent radical resection of stage III colorectal cancer, conducted by the National Surgical Adjuvant Study of Colorectal Cancer 
Table 5 AEs during 1-5 courses of treatment (6 months) in each group

* Pearson's chi-square test

\begin{tabular}{|c|c|c|c|c|c|}
\hline & \multicolumn{2}{|c|}{ Control group $(n=531)$} & \multicolumn{2}{|c|}{ Study group $(n=532)$} & \multirow{2}{*}{$\begin{array}{l}\text { Any grade, } \\
p \text { value* }\end{array}$} \\
\hline & Any grade $(\%)$ & $\geq \operatorname{Grade} 3(\%)$ & Any grade $(\%)$ & $\geq$ Grade $3(\%)$ & \\
\hline $\mathrm{Hb}$ & 31.6 & 0.0 & 26.1 & 0.4 & 0.050 \\
\hline WBC & 13.2 & 0.0 & 13.3 & 0.4 & 1.000 \\
\hline Neut & 8.7 & 0.4 & 9.2 & 1.5 & 0.830 \\
\hline Plt & 5.3 & 0.0 & 6.8 & 0.0 & 0.367 \\
\hline AST & 23.5 & 3.4 & 20.5 & 1.9 & 0.237 \\
\hline ALT & 24.9 & 4.7 & 22.2 & 1.9 & 0.312 \\
\hline Al-p & 11.9 & 0.8 & 12.4 & 0.4 & 0.851 \\
\hline T-Bil & 25.4 & 1.9 & 24.2 & 0.8 & 0.671 \\
\hline BUN & 6.0 & 0.2 & 3.4 & 0.0 & 0.044 \\
\hline Creatinine & 6.6 & 0.0 & 5.1 & 0.0 & 0.299 \\
\hline Anorexia & 26.4 & 3.8 & 18.6 & 1.5 & $<0.01$ \\
\hline Nausea & 20.5 & 1.1 & 11.5 & 0.8 & $<0.01$ \\
\hline Vomiting & 8.5 & 0.2 & 3.6 & 0.4 & $<0.01$ \\
\hline Stomatitis & 13.4 & 1.1 & 8.6 & 0.0 & 0.014 \\
\hline Diarrhea & 28.1 & 7.2 & 14.8 & 2.4 & $<0.01$ \\
\hline Rash & 6.8 & 0.2 & 5.6 & 0.4 & 0.449 \\
\hline Hand-foot & 8.5 & 0.8 & 7.7 & 0.2 & 0.655 \\
\hline Alopecia & 1.9 & 0.0 & 1.9 & 0.0 & 1.000 \\
\hline Fatigue & 21.8 & 2.6 & 16.7 & 1.3 & 0.036 \\
\hline
\end{tabular}

Table 6 AEs during 6-10 courses of treatment and during 11-15 courses of treatment in the study group

\begin{tabular}{|c|c|c|c|c|}
\hline & \multicolumn{2}{|c|}{$\begin{array}{l}\text { Study group }(n=403) \\
\text { in } 6-10 \text { courses }\end{array}$} & \multicolumn{2}{|c|}{$\begin{array}{l}\text { Study group }(n=333) \\
\text { in } 11-15 \text { courses }\end{array}$} \\
\hline & $\begin{array}{l}\text { Any grade } \\
(\%)\end{array}$ & $\begin{array}{l}\geq \text { Grade } 3 \\
(\%)\end{array}$ & $\begin{array}{l}\text { Any grade } \\
(\%)\end{array}$ & $\begin{array}{l}\geq \text { Grade } 3 \\
(\%)\end{array}$ \\
\hline $\mathrm{Hb}$ & 20.8 & 0.7 & 17.7 & 0.0 \\
\hline WBC & 13.4 & 0.0 & 12.9 & 0.6 \\
\hline Neut & 7.9 & 0.7 & 6.0 & 0.6 \\
\hline Plt & 10.2 & 0.0 & 10.5 & 0.3 \\
\hline AST & 18.6 & 0.0 & 14.7 & 0.6 \\
\hline ALT & 18.6 & 0.2 & 12.9 & 0.6 \\
\hline Al-p & 12.7 & 0.0 & 13.2 & 0.3 \\
\hline T-Bil & 27.0 & 0.5 & 28.8 & 0.0 \\
\hline BUN & 3.2 & 0.0 & 4.8 & 0.0 \\
\hline Creatinine & 2.7 & 0.0 & 3.6 & 0.0 \\
\hline Anorexia & 8.7 & 0.5 & 4.8 & 0.0 \\
\hline Nausea & 4.7 & 0.0 & 3.0 & 0.0 \\
\hline Vomiting & 3.2 & 0.0 & 0.9 & 0.0 \\
\hline Stomatitis & 7.7 & 0.0 & 5.4 & 0.0 \\
\hline Diarrhea & 9.7 & 0.2 & 6.6 & 0.0 \\
\hline Rash & 5.0 & 0.0 & 3.6 & 0.0 \\
\hline Hand-foot & 9.9 & 1.0 & 7.8 & 0.3 \\
\hline Alopecia & 0.7 & 0.0 & 0.0 & 0.0 \\
\hline Fatigue & 9.7 & 0.5 & 6.6 & 0.0 \\
\hline
\end{tabular}

(NSAS-CC), the completion rate of 1 year of treatment was $80.3 \%$ [10]. The treatment completion rates in both of these studies were higher than that in the study group of the present study $(56.3 \%)$. The toxicity associated with UFT plus leucovorin is stronger than that associated with UFT alone, and it may affect the completion rates of long-term adjuvant chemotherapy. Our results suggest that the use of modified treatment regimens, such as 5 days of treatment followed by 2 days of rest, is needed to maintain long-term drug compliance in UFT and leucovorin chemotherapy.

The incidence of grade 3 or higher diarrhea in our study was $7.2 \%$ in the control group and $2.4 \%$ in the study group. In a recent phase III study [adjuvant chemotherapy trial of TS-1 for colon cancer (ACTS-CC) trial] comparing 6 months of UFT plus leucovorin with S-1 as adjuvant chemotherapy in patients with stage III colon cancer, the incidence of grade 3 or higher diarrhea was $5.5 \%$ in the UFT plus leucovorin group [16], similar to our results. In the NSABP C06 trial, performed in Western countries, the incidence of grade 3 or higher diarrhea was as much as $29.4 \%$ in the UFT plus leucovorin group [5]. The difference in the incidence of severe diarrhea between Western countries and Japan might be attributed to racial differences. In the present study, the incidence of diarrhea in any grade at 6 months was lower in the 
study group (15.0\%) than in the control group (28.3\%). Therefore, the treatment schedule which consists of 5 days of UFT plus LV and 2 days of treatment rest may be a more feasible treatment option for use in Western countries.

In conclusion, oral UFT plus leucovorin was associated with a low incidence of AEs, indicating that it is a safe regimen as adjuvant chemotherapy. In particular, our results showed that the treatment schedule which consists of 5 days of UFT plus LV and 2 days of treatment rest was associated with a lower incidence of AEs when treatment continues more than 6 months or longer period. Because 5 days of treatment followed by 2 days of rest is not associated with a lower dose intensity than the standard regimen for UFT plus leucovorin, it is a useful treatment option from the viewpoint of toxicity.

Acknowledgments The JFMC33-0502 study was conducted by the Japanese Foundation for Multidisciplinary Treatment of Cancer (JFMC). We are indebted to all patients and collaborative investigators who cooperated with this study. The participating hospitals are shown in the supplementary information.

Conflict of interest Yoshihiro Kakeji has received honoraria from Taiho Pharmaceutical Co., Ltd, Tokyo, Japan. Chikuma Hamada has served on the advisory board and received research funding from Taiho Pharmaceutical. The other authors have declared no conflict of interest.

Open Access This article is distributed under the terms of the Creative Commons Attribution License which permits any use, distribution, and reproduction in any medium, provided the original author(s) and the source are credited.

\section{References}

1. NCCN practice guideline in oncology: antiemesis. Ver. 3 (2013)

2. O'Connell MJ, Laurie JA, Kahn M, Fitzgibbons RJ Jr, Erlichman C, Shepherd L, Moertel CG, Kocha WI, Pazdur R, Wieand HS, Rubin J, Vukov AM, Donohue JH, Krook JE, Figueredo A (1998) Prospectively randomized trial of postoperative adjuvant chemotherapy in patients with high-risk colon cancer. J Clin Oncol 16(1):295-300

3. Andre T, Colin P, Louvet C, Gamelin E, Bouche O, Achille E, Colbert N, Boaziz C, Piedbois P, Tubiana-Mathieu N, BoutanLaroze A, Flesch M, Buyse M, de Gramont A (2003) Semimonthly versus monthly regimen of fluorouracil and leucovorin administered for 24 or 36 weeks as adjuvant therapy in stage II and III colon cancer: results of a randomized trial. J Clin Oncol 21(15):2896-2903. doi:10.1200/JCO.2003.10.065

4. Haller DG, Catalano PJ, Macdonald JS, O'Rourke MA, Frontiera MS, Jackson DV, Mayer RJ (2005) Phase III study of fluorouracil, leucovorin, and levamisole in high-risk stage II and III colon cancer: final report of Intergroup 0089. J Clin Oncol 23(34):8671-8678. doi:10.1200/JCO.2004.00.5686

5. Lembersky BC, Wieand HS, Petrelli NJ, O'Connell MJ, Colangelo LH, Smith RE, Seay TE, Giguere JK, Marshall ME, Jacobs AD, Colman LK, Soran A, Yothers G, Wolmark N (2006) Oral uracil and tegafur plus leucovorin compared with intravenous fluorouracil and leucovorin in stage II and III carcinoma of the colon: results from National Surgical Adjuvant Breast and Bowel Project Protocol C-06. J Clin Oncol 24(13):2059-2064. doi:10.12 00/JCO.2005.04.7498

6. Andre T, Boni C, Mounedji-Boudiaf L, Navarro M, Tabernero J, Hickish T, Topham C, Zaninelli M, Clingan P, Bridgewater J, Tabah-Fisch I, de Gramont A (2004) Oxaliplatin, fluorouracil, and leucovorin as adjuvant treatment for colon cancer. $\mathrm{N}$ Engl $\mathrm{J}$ Med 350(23):2343-2351. doi:10.1056/NEJMoa032709

7. Twelves C, Wong A, Nowacki MP, Abt M, Burris H 3rd, Carrato A, Cassidy J, Cervantes A, Fagerberg J, Georgoulias V, Husseini F, Jodrell D, Koralewski P, Kroning H, Maroun J, Marschner N, McKendrick J, Pawlicki M, Rosso R, Schuller J, Seitz JF, Stabuc B, Tujakowski J, Van Hazel G, Zaluski J, Scheithauer W (2005) Capecitabine as adjuvant treatment for stage III colon cancer. $\mathrm{N}$ Engl J Med 352(26):2696-2704. doi:10.1056/NEJMoa043116

8. Sargent D, Sobrero A, Grothey A, O'Connell MJ, Buyse M, Andre T, Zheng Y, Green E, Labianca R, O'Callaghan C, Seitz JF, Francini G, Haller D, Yothers G, Goldberg R, de Gramont A (2009) Evidence for cure by adjuvant therapy in colon cancer: observations based on individual patient data from 20,898 patients on 18 randomized trials. J Clin Oncol 27(6):872-877. doi:10.1200/JCO.2008.19.5362

9. Sadahiro S, Suzuki T, Ishikawa K, Nakamura T, Tanaka Y, Masuda T, Mukoyama S, Yasuda S, Tajima T, Makuuchi H, Murayama C (2003) Recurrence patterns after curative resection of colorectal cancer in patients followed for a minimum of ten years. Hepatogastroenterology 50(53):1362-1366

10. Akasu T, Moriya Y, Ohashi Y, Yoshida S, Shirao K, Kodaira S (2006) Adjuvant chemotherapy with uracil-tegafur for pathological stage III rectal cancer after mesorectal excision with selective lateral pelvic lymphadenectomy: a multicenter randomized controlled trial. Jpn J Clin Oncol 36(4):237-244. doi:10.1093/jjco/ hyl014

11. Kato T, Ohashi Y, Nakazato H, Koike A, Saji S, Suzuki H, Takagi H, Nimura Y, Hasumi A, Baba S, Manabe T, Maruta M, Miura K, Yamaguchi A (2002) Efficacy of oral UFT as adjuvant chemotherapy to curative resection of colorectal cancer: multicenter prospective randomized trial. Langenbecks Arch Surg 386(8):575-581. doi:10.1007/s00423-002-0278-x

12. Kato H, Ichinose Y, Ohta M, Hata E, Tsubota N, Tada H, Watanabe Y, Wada H, Tsuboi M, Hamajima N (2004) A randomized trial of adjuvant chemotherapy with uracil-tegafur for adenocarcinoma of the lung. N Engl J Med 350(17):1713-1721. doi:10.10 56/NEJMoa032792

13. Shimada Y, Hamaguchi T, Moriya Y, Saito N, Kanemitsu Y, Takiguchi N, Ohue M, Kato T, Takii Y, Sato T, Tomita N, Yamaguchi S, Akaike M, Mishima H, Kubo Y, Mizusawa J, Nakamura K, Fukuda H (2012) Randomized phase III study of adjuvant chemotherapy with oral uracil and tegafur plus leucovorin versus intravenous fluorouracil and levofolinate in patients (pts) with stage III colon cancer (CC): final results of Japan Clinical Oncology Group study (JCOG0205). J Clin Oncol 30(Suppl). Abstract no 3524

14. Watanabe T, Itabashi M, Shimada Y, Tanaka S, Ito Y, Ajioka Y, Hamaguchi T, Hyodo I, Igarashi M, Ishida H, Ishiguro M, Kanemitsu Y, Kokudo N, Muro K, Ochiai A, Oguchi M, Ohkura Y, Saito Y, Sakai Y, Ueno H, Yoshino T, Fujimori T, Koinuma N, Morita T, Nishimura G, Sakata Y, Takahashi K, Takiuchi H, Tsuruta O, Yamaguchi T, Yoshida M, Yamaguchi N, Kotake K, Sugihara K (2012) Japanese Society for Cancer of the Colon and Rectum (JSCCR) guidelines 2010 for the treatment of colorectal cancer. Int J Clin Oncol 17(1):1-29. doi:10.1007/ s10147-011-0315-2

15. Neugut AI, Matasar M, Wang X, McBride R, Jacobson JS, Tsai WY, Grann VR, Hershman DL (2006) Duration of adjuvant 
chemotherapy for colon cancer and survival among the elderly. $\mathbf{J}$ Clin Oncol 24(15):2368-2375. doi:10.1200/JCO.2005.04.5005

16. Mochizuki I, Takiuchi H, Ikejiri K, Nakamoto $\mathrm{Y}$, Kinugasa Y, Takagane A, Endo T, Shinozaki H, Takii Y, Takahashi Y, Mochizuki H, Kotake K, Kameoka S, Takahashi K, Watanabe
T, Watanabe M, Boku N, Tomita N, Matsubara Y, Sugihara K (2012) Safety of UFT/LV and S-1 as adjuvant therapy for stage III colon cancer in phase III trial: ACTS-CC trial. Br J Cancer 106(7):1268-1273. doi:10.1038/bjc.2012.86 